\title{
DIZER O CORPO EM ESPAÇO PÚBLICO: ANÁLISE SEMIÓTICA DE PUBLICAÇÃO ONLINE SEXISTA ${ }^{1}$
}

\author{
TALKING ABOUT THE BODY IN PUBLIC SPACE: SEMIOTIC ANALYSIS OF A \\ SEXIST ONLINE POST
}

\author{
Naiane Vieira dos Reis ${ }^{2}$ \\ Jordan Oliveira da Silva ${ }^{3}$
}

Resumo: Este trabalho objetiva analisar o discurso sobre a mulher no espaço público em uma publicação em rede social digital, observando as construções sociais que perduram e implicam na exclusão do feminino. Como subsídio teórico, lançamos mão das discussões sobre gênero, pelas perspectivas da história e dos estudos de gênero, tendo em vista a inscrição da mulher nos âmbitos de participação social, além de considerar categorias de análise da semiótica discursiva para a análise de dados. O corpo, nesses discursos enunciados em espaço público, é instância de denúncia e negociação de direitos de gênero.

Palavras-chave: gênero; mulher; sexismo; semiótica; interação

\begin{abstract}
This work aims to analyze the discourse about women in the public areas in a post made in a digital social network, observing the social constructions that persist and imply in the exclusion of the feminine. As a theoretical subsidy, we used the discussions on gender, the perspectives of history and gender studies, in view of the inclusion of women in the areas of social participation, as well as considering categories of analysis from the discursive semiotics for data analysis. The body, in these speeches enunciated in public areas, is an instance of denunciation and negotiation of gender rights.
\end{abstract}

Keywords: gender; woman; sexism; semiotics; interaction.

\section{Introdução}

Estamos acostumados a valorizar a mulher, não como personalidade, com qualidades e defeitos individuais, independente de suas sensações

\footnotetext{
${ }^{1}$ Este trabalho foi apresentado no I Encontro do Grupo de Estudos Linguísticos e Literários da Região Norte, Rio Branco - AC, 2017.

${ }^{2}$ Doutoranda em Letras pela Universidade Federal do Tocantins - UFT, campus de Araguaína. Desenvolve pesquisa em semiótica, literatura e gênero. E-mail: naianevieira@hotmail.com

${ }^{3}$ Docente do Instituto Federal do Maranhão - IFMA nas disciplinas de Português e Inglês.
} 
psicofiosiológicas. Para nós, a mulher só tem valor como acessório do homem. O homem, marido ou amante, projeta sobre a mulher sua luz; é a ele e não a ela que tomamos em consideração como verdadeiro elemento determinante da estrutura espiritual e moral da mulher. Em troca, quando valorizamos a personalidade do homem, fazemos por antecipação uma total abstração de seus atos no que diz respeito às relações sexuais.

A personalidade da mulher, pelo contrário, valoriza-se em relação à sua vida sexual.

A nova mulher e a moral sexual, de Alexandra Kolontai (2011)

A compreensão das condições sociais vividas pelas mulheres na atualidade se dá a partir de um olhar ampliado sobre a questão do gênero, pois é necessário reconhecer, de início, que são vários e variados os recortes de pesquisa no ambiente acadêmico, por exemplo. Embora seja bastante notificado nos jornais de todo o mundo e pesquisado nos espaços universitários, com políticas públicas pensadas e repensadas com vista à resolução de um desafio para a sociedade contemporânea, o problema da violência contra a mulher tem vários contornos e ainda merece bastante atenção. Se o momento atual é alardeado pelas mídias como sendo de conquistas por direitos sociais e políticos, o cenário brasileiro também revela que as tensões e disputas estão cada vez mais intensas, com conflitos diários que muitas vezes apontam para grandes retrocessos no tocante à vida e à segurança das mulheres.

No ano de 2015, o Exame Nacional do Ensino Médio (Enem) adotara como tema da Redação, para a qual o candidato recebe metade da nota desse processo que também é seletivo para entrada em uma instituição de ensino superior, a "Persistência da violência contra a mulher na sociedade brasileira'. Trouxe nos seus quatro textos motivadores dados sobre o número de assassinato de mulheres, tipos de violência sofridos, cartaz de alerta sobre o crime de feminicídio e, por fim, o número de processos instaurados na justiça a partir da efetivação da Lei $\mathrm{n}^{\circ}$ 11.340/06, batizada de Lei Maria da Penha. Por se tratar da $2^{\circ}$ maior prova de acesso ao ensino superior do mundo, de acordo com os dados do Portal Brasil - MEC ${ }^{4}$, com mais de 8 milhões de candidatos no ano em que o assunto fora privilegiado, o Enem demandou de seus candidatos, para além da dissertação sobre a temática da violência contra a mulher, a discussão sobre sua permanência, sua insistência, sua persistência. Como o exame exige na elaboração do texto a formulação de uma proposta de intervenção ao problema focalizado,

\footnotetext{
${ }^{4}$ http://portal.mec.gov.br/ultimas-noticias/418-enem-946573306/31151-a-segunda-maior-prova-de-acesso-aoensino-superior-do-mundo (Acessado em 08 de janeiro de 2018).
} 
também cabia ao candidato pensar estratégias que superassem ou apresentassem alternativas à temática em questão, indicando avanços quanto à vulnerabilidade física (entre outros aspectos) que essa parte da sociedade sofre. Assim, o Enem, a partir da adoção de tipo textual dissertativo-argumentativo, já enunciava que a violência contra a mulher trata de um evento extenso, que tem atravessado diferentes tempos, épocas e gerações, a despeito do ganho de direitos dessa parcela da população.

$\mathrm{Na}$ contramão dessa discussão focalizada pelo exame e de interesse de diversas instâncias sociais, um material didático destinado ao público de ensino fundamental questionava os estudantes, em atividade de leitura, sobre a validade da punição legal do agressor, demandado de adolescentes posicionamento sobre um texto de lei que disputou durante décadas sua efetivação, tendo em vista a garantia da integridade física das mulheres. Nesse sentido, é notável que as tensões no que concerne à temática estão evidenciadas no campo da educação, havendo avanços e retrocessos.

No ano de 2017, ao divulgar seu relatório "A distância que nos une: um retrato das desigualdades brasileiras", a OXFAN (2017) fez projeções que evidenciaram também o lugar de desigualdade e violência que se agarra à figura da mulher: há previsão de equiparação salarial entre homens e mulheres para o ano de 2047 e de renda entre negros e brancos para apenas 2089. Embora trate da questão de gênero e raça de modo dual e distinto, a intersecção desses dois fatores resulta no recorte também de classe, pois ser mulher e negra é ocupar a base da pirâmide social, na posição com menos privilégios e direitos, geralmente sofrendo os maiores impactos da desigualdade socioeconômica, que vai se revelando como também de gênero (DAVIS, 2017).

A partir problemática depreendida dos dois textos acima mencionados, o Enem e o relatório da OXFAN, em que o sujeito mulher é compreendido como tensionado, vulnerável às violências física, social e econômica, empreendemos pelos menos duas direções de leituras e posicionamentos sociais distintos sobre o lugar da mulher. Por um lado, há discursos que concorrem para a elaboração de contra-narrativas que apontam para novas construções de sentido sobre o que é ser mulher, evidenciando que o corpo submetido à violência, principalmente aquela de caráter doméstico e praticada por quem tem relação emocional e afetiva com a vítima, pode dar lugar a uma "sujeita" livre. Por outro, porém, há dizeres e práticas que corroboram os dados quantitativos evidenciados pela pesquisa da OXFAN, indicando que a mulher ainda persistirá na condição de subalternizada (e violentada) - no 
aspecto econômico, pelo menos - pelas próximas longas décadas, sendo subjugada ao dizer do outro, de ordem patriarcal e masculina, que determina seu lugar e valor. É justamente nessa tensão entre o já estabelecido e o que aparentemente é novo no discurso sobre gênero, corpo e direito da mulher que se situa nossa discussão.

Considerando as tensões em torno da questão de gênero, especialmente no momento atual em que um projeto de lei, alegando garantir a neutralidade política no ensino escolar, intenta censurar e criminalizar as discussões sobre gênero e sexualidade na educação básica num país com números alarmantes de feminicídio, a discussão sobre a mulher é marcada por alguns avanços e retrocessos no âmbito sócio-político. Situando a abordagem nesse campo conflituoso, nos dedicamos, neste trabalho, a tratar da temática "violência contra a mulher", observando especificamente algumas narrativas sobre o corpo, tendo em vista o espaço e a identidade atribuídos a essa "sujeita" social. Para tanto, elegemos como corpus uma publicação em rede social de um cantor nacionalmente conhecido que, em referência a um texto publicado em um jornal de grande circulação sobre liberdade e arte, seleciona e altera a fotografia de perfil de uma artista com dizeres e figuras, emitindo sanção negativa sobre o lugar social ocupado por uma mulher, o espaço público, a partir do pretenso julgamento de sua performance sexual/social ${ }^{5}$.

Para nossa discussão, abordamos a questão da mulher à luz dos estudos de gênero, a partir das perspectivas historiográficas e discursivas sobre esse sujeito ao longo das mudanças sociais, e fazemos uso do aporte teórico da semiótica discursiva, mais precisamente no tocante à tensividade (ZILBERBERG, 2011) e aos regimes de interação (LANDOWSKI, 2014), selecionando, portanto, categorias que vão para além do modelo de análise standard do plano do conteúdo. Ao focalizarmos os discursos em disputa na atualidade, evidenciados nas relações estabelecidas principalmente nas redes sociais digitais, nota-se que há tanto dizeres que repercutem ideais mais conservadores e opressores no que diz respeito às minorias sociais tradicionalmente estabelecidas neste país (negros, comunidade LGBT+, mulheres, deficientes, entre outros), a partir de relações entre sujeitos que apontam para a regularidade e programação, quanto àqueles que fazem mover e modificar narrativas e trajetórias socialmente oprimidas, ajustando-se pelas demandas da sociedade e dos sujeitos que se veem à sua margem. Nesse sentido, são observados diferentes dizeres, enunciados principalmente

5 A imagem que é corpus desta análise também é focalizada no seguinte artigo de opinião: http://www.viomundo.com.br/denuncias/a-reacao-do-inutil-roger-a-entrevista-de-adriana-varejao.html 
pelos movimentos sociais, que disputam com denominada "onda reacionária" os novos modos de construir as relações em sociedade.

\section{Ser mulher pelo dizer do outro}

A disputa pelo domínio das narrativas atinge o ápice em momentos que um grupo, em posição subalterna, alcança algumas posições de poder ou, melhor dizendo, faz movimentar estruturas rígidas de dominação. Como aponta Butler (2016) ao discutir a construção social do "sexo", as normas regulatórias determinam práticas e comportamentos que, por isso mesmo, são estabelecidas no âmbito do conflito, uma vez que é forçoso: "são as instabilidades, as possibilidades de rematerialização [...] que marcam um domínio no qual a força da lei regulatória pode se voltar contra ela mesma para gerar rearticulações que colocam em questão a força hegemônica daquela mesma lei regulatória” (BUTLER, 2016, p. 154). Podemos entender aí que as rematerializações ocorrem em decorrência das diferenças que desestabilizam as identidades, que são impostas pelos vetores de forças e relações de poder, mas também são disputadas (SILVA, 2014, p. 81). Nesse sentido, a identidade do sujeito mulher vai sofrendo modificações no corpo social justamente em decorrência dessas disputas: ocupa o mercado de trabalho, o espaço público, a educação, o direito ao voto, o poder político, o direito ao controle da reprodução etc. Embora considerados como avanços, é notável que tais mudanças foram feitas também contabilizando perdas: a ocupação do trabalho está até os dias de hoje marcada pela desigualdade salarial e vulnerabilidade física e psicológica, tendo em vista os inúmeros casos de assédio sexual e moral no ambiente laboral; embora qualificadas, a mulheres continuam preteridas no mercado de trabalho, especialmente em cargos de poder; o voto pouco refletiu na participação das mulheres na vida política, já que são poucas as que ocupam cargos no executivo, legislativo ou judiciário, entre inúmeras outras circunstâncias.

A partir de observações sobre as afetividades, profundamente modificadas pelas novas relações com o trabalho e, consequentemente, com a sociedade, Alexandra Kolontai (2011) faz apontamentos sobre a condição oprimida da mulher, seja ela burguesa ou da classe trabalhadora, que nos parecem pertinentes ainda nos dias atuais. Publicado em 1918, o ensaio “A nova mulher e a moral sexual”, que já completa seu centenário, aponta justamente para o não-lugar ocupado e o não-poder-ser da mulher fora da relação com o homem. Como destacado em nossa epígrafe, a mulher, no conjunto de suas performances sociais, seja 
aceitando ou rejeitando o contrato do "bela, recatada e do lar", constitui-se como artefato que compõe o capital simbólico que, aí sim, é definidor da condição do homem em sociedade: ele é aquilo que possui. Assim, a sexualidade é condenatória para a mulher, quando explorada fora dos limites maritais.

Ao investigar a condição da mulher no trabalho e na sociedade ao longo da história, focalizando especificamente a sua inserção no mercado de trabalho remunerado a partir do capitalismo industrial, Michelle Perrot (2017) observa um novo modo de organização social a partir da instauração da burguesia como classe de poder político e econômico, considerando mais especificamente o caso francês. Embora se dedique a observar a construção histórica da mulher na sociedade francesa, da mais à menos privilegiada, Perrot (2017) destaca aspectos que são comuns nas mais diversas culturas, já que focaliza justamente o apagamento da figura feminina na construção das diferentes sociedades e organizações sociais, embora tais sujeitas também protagonizassem a esfera do trabalho, política, ciência, educação etc. A autora observa a atuação da mulher na sociedade urbana a partir de oposições, tendo em vista o recorte no século XIX burguês: mulher $\mathrm{x}$ homem, interno $\mathrm{x}$ externo, privado $\mathrm{x}$ público, subjetivo x objetivo. Sendo as primeiras características desprezadas, pois caracterizadoras do feminino, a essa sujeita também é atribuído o silêncio na história, política e sociedade: "Trabalhadora ou ociosa, doente, manifestante, a mulher é observada e descrita pelo homem", sem possibilidade, portanto, de produzir suas próprias narrativas (PERROT, 2017, p. 198).

A abordagem historiográfica focaliza bastante o século XIX, pois trata-se do momento em que a classe burguesa se consolida como produtora dos bens culturais e definidora do padrão de comportamento, que funda uma moralidade baseada no controle da sexualidade e, portanto, da vida da mulher. Concomitante à sua entrada na produção industrial, o trabalho feminino, mesmo sendo das classes menos privilegiadas, é vigiado e regulamentado por padrões comportamentais burgueses, que teme a saída da mulher do ambiente doméstico, pois pode levá-la à degeneração moral e à "desagregação da família" (RAGO, 2015, p. 588). Esse olhar para o passado é fundamental para compreender os padrões de valor comportamental na atualidade. Assim, a mulher nomeada puta, desavergonhada, sem valor ou qualquer outra nomenclatura que evidencie sua sanção negativa pela sociedade é aquela que, fora da casa, não consegue cumprir com o que seria considerado como obrigações familiares: cuidados com os filhos, o lar, o marido. 
O olhar sobre a construção histórica de gênero tal como a concebemos e vivenciamos atualmente é necessário para compreendermos os aspectos sociais e políticos que organizam e motivam discursos de ódio e de exclusão, tal como selecionamos para a nossa análise. Se a história revela um passado construído sobre a submissão da mulher na vida conjugal e no mercado de trabalho, tendo em vista a ratificação da tradição patriarcal e de uma sociedade de poder exclusivamente masculina, no presente vemos timidamente mulheres ocupando os espaços de decisão política e econômica, mas ainda subjugada a uma moral que não afeta a atuação dos homens no meio social.

\section{$2 \mathrm{O}$ funcionamento da rede social e o discurso intolerante}

Em uma polêmica sobre sexualidade e "valores familiares" em ambientes públicos que circula na internet que, aliás, repercute cada vez mais problemáticas de teor semelhante, diferentes sujeitos sociais, alimentados pelos discursos mais conservadores e à direita da política nacional, denunciam o caráter degenerado, promíscuo e indecente das obras e instalações de arte em museus e galerias. Se o evento parece incoerente frente aos dados que revelam o número de visitação nesses espaços culturais, apresentando apenas $10 \%$ da população brasileira como frequentadora e apreciadora desses tipos de $\operatorname{arte}^{6}$, um olhar mais atento ao comportamento dos sujeitos na internet indica as razões dessa espécie de reação em massa.

Como aponta Luiza Silva (2017) em sua análise sobre os discursos políticos que circulavam em uma rede social na ocasião do impeachment da presidenta Dilma Rousseff, os sujeitos repercutem seus dizeres a outros que apontam para a mesma direção e anulam o diferente, resultando numa narrativa homogênea sobre o evento em foco. Observação da interação a partir das contribuições da sociossemiótica aponta que, embora tenha circulado grandes textos que argumentam sobre um determinado ponto de vista, a homogeneidade dos discursos resulta em uma programação, caracterizada pela regularidade, pois os sujeitos convergem para a mesma direção, sem haver, possivelmente, disputa e negociação ou convencimento de um interlocutor divergente, o que resultaria num regime nomeado de manipulação (SILVA, 2017, p. 4). Nesse sentido, embora cause estranhamento que de norte a sul do país haja posicionamento sobre o tipo de arte degenerada, já que dados dão conta do

6 Este dado consta na notícia da Agência Brasil sobre o relatório realizado pela Fecomércio-RJ: http://agenciabrasil.ebc.com.br/cultura/noticia/2017-04/brasileiros-frequentam-mais-teatros-e-cinemas-dizpesquisa 
desconhecimento massivo da população sobre as criações artísticas, a dinâmica das redes sociais evidencia que a inscrição de sujeitos em uma discussão, independentemente de seu conhecimento sobre o objeto de debate, acontece devido ao modo como se organizam as interações nas redes.

Ao tratarem dos comportamentos usuários da web, Gee e Hayes (2011) apontam que os internautas tendem a alinhar e unir-se a outros sujeitos que repercutem seus discursos. Além disso, o discurso intolerante, segundo os autores, vai tornando-se ainda mais intenso à medida que encontra outros dizeres que o ratificam. Ao observar o efeito de veridicção produzido pelos discursos em massa difundidos nas redes, Barros (2015, p. 22) salienta que

O destinador desses discursos é colocado na posição de sujeito do saber e seu destinatário, devido à interatividade intensa [...], deles se considera em boa parte, também como autor-destinador. Esse destinatário, assim construído, acredita e confia nos discursos que também são seus. (BARROS, 2015, p. 22) [grifos da autora]

No debate em torno do pretenso conteúdo de exposições de arte Brasil afora, a repercussão de falas de alguns grupos, páginas ou sujeitos em distintas e variadas redes sociais se dá em função do alinhamento ideológico dos sujeitos destinatários da interação virtual. Assim, não se trata meramente de censurar obras de arte, mas de fortalecer os discursos em favor de uma narrativa única, que exclui e renega tudo aquilo que parece ameaçar a ordem vigente. Embora coexistam diferentes discursos sociais sobre a sexualidade e o gênero, por exemplo, é notável que haja pouco movimento de mistura, isto é, a união, junção e participação, o diálogo com aquilo que é diferente, heterogênero, tendo em vista a construção de um discurso novo. A dinâmica da rede social é operada pelo princípio da exclusão, pela triagem, em que anula o diferente e une o igual (FIORIN, 2008).

A partir da compreensão desses processos que organizam a dinâmica das redes sociais, dedicamo-nos a analisar uma postagem em que a questão do gênero é privilegiada.

\section{0 combate à arte degenerada}

Em meados do mês de setembro do ano de 2017, em meio à polêmica sobre uma exposição de arte realizada no sul do país, patrocinada por uma organização financeira e suspensa após intensa repercussão negativa, um músico de uma famosa banda de rock dos anos 70-80 repercutiu uma publicação do blog "Agora é que são elas", do Jornal online Folha de São Paulo. O texto repercutido pelo músico tratava-se de uma entrevista com a artista 
plástica Adriana Varejão, uma das expositoras censuradas, sobre o conteúdo de suas obras, em que defendia a liberdade de criar e exibir objetos artísticos.

O blog foi criado na ocasião de um movimento em diversas redes sociais, quando foram denunciados de modo anônimo ou não casos de assédio (\#meuprimeiroassedio) nos mais diferentes setores das vidas das mulheres no Brasil em 2015. Essa seção do jornal serviria, portanto, como espaço para tratar especificamente de questões que afetam as mulheres, sendo costumeiramente publicações de caráter feminista.

Selecionamos para análise o print da postagem no Twitter, em forma de imagem, que repercutiu também no Facebook e em páginas de notícias. Não vamos considerar o entorno da imagem em sua página de publicação, já que em diferentes sítios há links e hipertextos diferentes relacionados ao que recortamos para a análise.

$\mathrm{Na}$ parte superior da imagem, estão inscritos os dizeres “Adriana Varejão: 'A arte deve ter liberdade total' https://t.co/vvLnNItAlI // fiz essa arte, Adriana. Tudo bem, né? Mostra pra criançada". É feita citação direta do título do texto jornalístico, em destaque pelo uso de aspas e, adiante, é apresentado um link para acessar a página do jornal com a entrevista da artista. Em seguida, como pode ser observado pelo vocativo (Adriana), a publicação direciona-se para sua interlocutora declarando uma ação ("fiz essa arte, Adriana"), e enuncia uma espécie de pedido de aprovação (“Tudo bem, né?”).

O locutor ocuparia a posição de destinatário, uma vez que demanda a aprovação do outro que estaria na posição de poder, do destinador. A reprodução de um trecho da entrevista que também dá título ao texto, articulada aos dizeres da postagem, evidencia que a penúltima frase se trata de uma pergunta retórica. Se "a arte deve ter liberdade total", o artista em questão não necessitaria de autorização para elaborar a sua. Na última frase, porém ("Mostra pra criançada"), o modo imperativo do verbo mostrar indica que o locutor é quem ocupa a posição de destinador, já que manipula o fazer do outro, tendo em vista o pedido ou ordem depreendido no enunciado.

O discurso, uma vez que dialoga com a polêmica vastamente difundida em torno da exposição de arte, que fora acusada de promover a prática de pedofilia, é da ordem da extensidade (ZILBERBERG, 2011), ecoando as diversas vozes sancionadoras da exposição. A última frase é polissêmica e remete, num primeiro momento, à sua negação: como a pedofilia seria condenada pelos internautas, aquela arte degenerada não poderia, portanto, ser exibida ao público infantil. 
Mais abaixo na imagem do print, há uma fotografia em que é reproduzida a figura da artista da altura da cintura até acima do rosto, com a face situada em direção frontal. A figura da artista está localizada no centro, mais à direita. A fotografia parece captar um momento de exposição de obras de artes, pois também é possível visualizar parte de uma tela e de sujeitos em posição sutilmente curvada, em observação à exposição.

A imagem está parcialmente rasurada, com um desenho em cor marrom e contornos negros, figurativizando um órgão sexual masculino. Da margem esquerda ao centro, em posição horizontal, o desenho/rasura está situado na altura da boca da figura da artista, sugerindo o ato de sexo oral. Sobre os olhos, mais ou menos alinhadas, estão inscritas duas figuras que remetem ao sinal de mais $(+)$ ou à imagem da cruz. Mais abaixo, na altura do peito, está notificada a inscrição PUTA.

Articulando o verbal ao visual, a publicação violenta e sexista pode ser fruto das mais distintas leituras. Uma delas refere-se ao medo do caráter transgressor da moral vigente nas leituras das obras, que para o público em grande parte não visitante de exposição apenas aponta para uma produção de sentido: induz o espectador a praticar pedofilia porque a nudez seria perigosa e violenta contra crianças. O objeto estético lido como ameaçador, seja de valores sociais ou da ordem vigente, foi vastamente discutido por Michèle Petit (2013) ao debater sobre a leitura de textos literários nas classes menos abastadas. Assim como a arte plástica, para o literário são produzidos significados coletivos, mas também subjetivos e privados, o que é observado como risco para aqueles que desejam dominar os sentidos e o corpo do outro. Nessa direção, o sentido produzido em segredo ou intimidade, na relação apreciador e obra de arte, é que precisa ser vigiado e controlado.

Por outro lado, observa-se, como aponta Barros (2016) ao analisar a intolerância perpetrada na web, o discurso de sanção do sujeito preconceituoso. Na publicação analisada, Varejão é julgada (é uma puta) e condenada (dois sinais de cruz), pois rompe com o contrato social vigente sobre o comportamento ditadamente feminino, sempre ligado à delicadeza, contrição e retidão.

Os dois sinais sobre os olhos remetem também à própria censura referida na entrevista dada pela artista, geralmente utilizada pelo jornalismo para ocultar a identidade de sujeitos protegidos pela justiça, sejam crianças ou suspeitos em processo de julgamento penal. Nesse sentido, a leitura pode apontar caminhos distintos: 1. a mulher, assim como a criança ou "menor", é inconsequente e necessita de um tutor/destinador para guiar-lhe, bem como 
para julgar seus atos; 2. a suspeita por um crime está em vias de ser julgada, como está enunciado na interlocução pretendida pela publicação. Ambos os casos indicam um sujeito sob a tutela do outro, tendo em vista a ruptura de contratos pelos atos publicamente vistos.

A palavra Puta é atualmente disputada pelas narrativas sobre gênero e sexualidade. Os valores conservadores indicam que a mulher deve cumprir com os contratos sociais de domínio apenas dos ambientes internos e interiores/domésticos, gozando da liberdade possibilitada restritamente no acordo conjugal pela figura do marido ou, para as não casadas, do pai. Toda mulher que rompe com o seu papel social preestabelecido é nomeada, portanto, de Puta, uma sanção negativa a partir do seu comportamento sexual, que, nesse caso, sempre é indicador da dignidade e respeitabilidade atribuídos à figura feminina. Por outro lado, o discurso feminista, que luta pela igualdade social entre os sexos, apropria-se do vocábulo justamente a partir dessa acepção do gênero, pois se ser puta é não estar de acordo com os valores do patriarcado, indica que a puta é a mulher que goza de liberdade e rompe com controle do corpo - e das mentes. Considerando que a artista plástica Varejão pertence às camadas sociais de privilégio, o seu corpo vai representar e manter a ideia conservadora do feminino, que é então compreendido como dócil, domesticado, puro e intocado. Sendo Puta, o contrato social é rompido e a mulher é sancionada negativamente, saindo da posição de privilégio e respeitabilidade e ocupando um lugar de exclusão e marginalidade, tendo em vista os valores morais conservadores e machistas.

Adriana Varejão não fora a única expositora, tampouco posicionou-se isoladamente sobre o episódio de censura a que foi submetida, mas foi o único alvo de $\sim$ crítica da postagem aqui analisada. Não fora contestada sua competência artística ou a sua capacidade intelectual, o que apresentava subsídios para ser avaliado, discutido ou criticado, tendo em vista o foco da polêmica. Se havia, no discurso moralista, a tentativa de manutenção da ideia de decência, de controle da sexualidade que fora ameaçado pelas obras de arte que discutem o corpo, a sua enunciação se dá pela da sexualização do corpo do outro, sempre o feminino. Se a mulher é discursivizada como sexual, todas as esferas de atuação social que lhe competem estão imbuídas de valores negativos, devendo, portanto, ser rejeitada.

Ao debater sobre a condição da mulher no mundo árabe, a médica Nawal el Saadawi (2002) relata que naquela sociedade o único valor que a mulher tem está atribuído à intocabilidade de seu corpo, tendo em vista o seu estado civil de solteira. Se o ocidente se debruça sobre o contexto de opressão feminina relatado pela pesquisadora com olhares 
condenatórios, observamos que a mulher da tradição não oriental também está subjugada ao mesmo sistema de valores patriarcais, pois seu corpo enuncia os valores que essa figura pode ter.

O evento focalizado nesta análise não está isolado ou se trata de um comportamento bastante específico de um único sujeito. Enunciar publicamente sanção negativa à atuação de mulheres ligadas ao espaço público é uma prática bastante recorrente oriunda dos mais diferentes setores da nossa sociedade. Não raro, personalidades públicas, como senadoras, deputadas, juízas entre outras, acionam a justiça em razão de ofensas sexistas proferidas abertamente contra elas, como é o caso de um apresentador de um programa de TV aberta que, assim como seu colega que elaborou a publicação aqui analisada, ofende de modo sexista uma deputada federal. A despeito da atividade ou competência das mulheres que se inscrevem no espaço público, costumeiramente críticas à sua atuação direcionam-se ao seu pretenso comportamento sexual. Embora lancem-se ao político, público, a sanção da sociedade realoca as mulheres no espaço privado do julgamento sexual.

\section{Algumas considerações}

Ao nos dedicamos a analisar uma publicação online de caráter sexista que ecoa muitos outros dizeres em momentos de tensão e disputa de narrativas, voltamos nossa atenção para os estudos sobre gênero para compreender o modo como se constroem os discursos que sempre relegam à mulher o espaço privado e a sanção moral-sexual. Se a publicação aqui selecionada para análise se refere a outro texto bastante preciso, o discurso ali ecoado pode ser também observado em outras esferas sociais, políticas, econômicas e históricas, com roupagens diferentes, mas apontando para direção similar: a mulher enquanto sujeito subalternizado

A publicação do músico resgata o sistema de valores a que está submetido o feminino: a mulher que rompe com o espaço doméstico e irrompe na esfera pública, como é o caso de uma galeria ou museu retratado na imagem, tem sua integridade moral submetida ao julgo e apreciação pública. Produzir narrativa, que no caso seria através da arte plástica, é permitido apenas quando submetido ao sistema de valores dominante, que atende à dinâmica que privilegia o masculino (PERROT, 2016).

Ao observar o campo de luta por direitos civis e políticos das mulheres, fazendo recorte de raça e classe, Angela Davis (2016) historiciza o campo de disputa pelo espaço 
público e debate sobre o impacto de políticas econômicas mais neoliberais nas liberdades e conquistas de direitos femininos (DAVIS, 2017). Em suas obras, a filósofa apresenta as mudanças no cenário político local ou global (quase sempre organizado sob um ponto de vista masculino) como indicadora da precarização da condição feminina. Nesse sentido, quanto mais conservadora e neoliberal, mais intensamente a mulher perde sua condição de sujeito e vai sendo relegada à condição de coisa, propriedade de representa o capital simbólico do patriarcado.

\section{Agradecimento:}

O presente trabalho foi realizado com apoio da Coordenação de Aperfeiçoamento de Pessoal de Nível Superior - Brasil (CAPES) - Código de Financiamento 001

\section{Referências}

BARROS, D. L. P. de. A complexidade discursiva na internet. CASA (Araraquara), v. 13, p. 13-31, 2015.

BARROS, D. L. P. de. Estudos discursivos da intolerância: o ator da enunciação excessivo. Cadernos de Estudos Linguísticos (UNICAMP), v. 58, p. 7-24, 2016.

BUTLER, J. Corpos que pesam: sobre os limites discursivos do "sexo". In: LOURO, G. L. (Org.). O corpo educado: pedagogias da sexualidade. $3^{\mathrm{a}}$ ed.; $2^{\mathrm{a}}$ reimp. Belo Horizonte: Autêntica Editora, 2016, p. 151 - 172.

DAVIS, A. Mulheres, Raça e Classe. Tradução de Heci Regina Candiani. São Paulo: Boitempo, 2016.

DAVIS, A. Mulheres, Cultura e Política. Tradução de Heci Regina Candiani. São Paulo:Boitempo, 2017.

FIORIN, J. L. Linguagem e interdisciplinaridade. Alea: Estudos Neolatinos, 2008. Vol. 10 (1), p. 29-53.

GEE, J. P.; HAYES, Elisabeth. Language and learning in the digital age. Routledge: New York, 2011.

KOLONTAI, A. A nova mulher e a moral sexual. $2^{\text {a }}$ ed. São Paulo: Expressão Popular, 2011.

LANDOWSKI, E. Interações arriscadas. São Paulo: Estação das Letras e Cores: Centro de Pesquisas Sociossemióticas, 2014.

OXFAM. 2017. "A distância que nos une: um retrato das desigualdades brasileiras". Disponível 
https://www.oxfam.org.br/sites/default/files/arquivos/Relatorio_A_distancia_que_nos_une.pd f. Acessado em 08/01/2018.

PERROT, M. Minha história das mulheres. $-2^{\circ}$ Ed., $3^{\mathrm{a}}$.reimp. São Paulo: Contexto, 2016. Os excluídos da história. $7^{\text {a }}$ ed. Rio de Janeiro/São Paulo: Paz e Terra, 2017.

PETIT, M. Leituras: do espaço íntimo ao espaço público. São Paulo: Editora 34, 2013.

RAGO, M. Trabalho feminino e sexualidade. In: PRIORE, M. L. M. (Org.). História das mulheres no Brasil. 10 a ed. $3^{\text {a }}$ reimp. São Paulo: Contexto, 2015, p. 578 - 606.

SAADAWI, N. El. A face oculta de Eva: as mulheres do mundo árabe. São Paulo: Global, 2002.

SILVA, L. H. O.. Manifestos políticos nas ruas e no Facebook, Document XII 'Sémiotique et engagement'. Actes Sémiotiques, v. 1, p. 1-12, 2017.

SILVA, T. T. A produção social da identidade e da diferença. In: SILVA, T.T. (Org.). Identidade e diferença: a perspectiva dos estudos culturais. 15 ed. Petrópolis, RJ: Vozes, 2014, p. $73-102$.

ZILBERBERG, C. Elementos de semiótica tensiva. São Paulo: Ateliê Editorial, 2011.

Recebido em 31 de maio de 2018. Aceito em 10 de outubro de 2018. 